\title{
Recombination Lasers in a Flowing Negative Glow Discharge
}

\author{
B. WERNSMAN, JORGE J. ROCCA, MEMBER, IEEE, HECTOR L. MANCINI, DANIEL SCHINCA, AND \\ J. O. TOCHO \\ (Invited Paper)
}

\begin{abstract}
A fast gas flow through a negative glow plasma creates an afterglow region where supercooled electrons are separated from energetic beam electrons to produce a population inversion by collisional recombination. We report spatially-resolved electron temperature measurements of the afterglow plasma showing electron temperatures in the range of 750-1100 K under steady-state conditions. A $4 \mathrm{~cm}$ long flowing hollow cathode discharge was used to obtain $\mathrm{CW}$ recombination laser oscillation in ArI. Collisional recombination of singly- and doubly-ionized metal vapor species in the same type of plasma has also produced pulsed laser action in infrared lines of $\mathrm{PbI}, \mathrm{ZnI}, \mathrm{PbII}$, and SnII. The addition of $\mathrm{H}_{2}$ is demonstrated to significantly increase the laser output intensity.
\end{abstract}

\section{INTRODUCTION}

W HILE pulsed recombination laser oscillation has been obtained in many different discharge and laser created plasmas [1]-[8], the conditions for $\mathrm{CW}$ recombination laser action are more difficult to obtain. Silfvast $\boldsymbol{e t}$ al. demonstrated recombination laser action for a period of $1 \mathrm{~s}$ in a low-voltage arc jet [9], and continuous wave recombination laser oscillation in CdI was obtained by Rocca in a flowing hollow cathode plasma [10]. This flowing negative glow discharge is to our knowledge the only device in which prolonged $\mathrm{CW}$ recombination laser action has been achieved to date.

Herein we discuss spatially-resolved spectral measurements of the electron temperature in the recombining plume of a flowing hollow cathode discharge. We also report $\mathrm{CW}$ recombination laser oscillation in ArI and pulsed recombination laser oscillation in several neutral and singly-ionized metal vapor species: PbI, ZnI, PbII, and SnII in the flowing afterglow of a $4 \mathrm{~cm}$ long discharge. A significant increase in the output intensity of the $\mathrm{ZnI}$ recombination laser was achieved by the increased plasma cooling resulting from the addition of hy-

Manuscript received November 22, 1989; revised April 16, 1990. This work was supported by the Air Force Office of Scientific Research under Grant 87-0290 and a National Science Foundation Presidental Young Investigator Award. D. Schinca was supported by CICPBA.

B. Wernsman and J. J. Rocca are with the Electrical Engineering Department, Colorado State University, Fort Collins, CO 80523

H. L. Mancini is with CITEFA/CONICET, Zufriategui 4380, 1603 Villa Martelli, Argentina.

D. Schinca and J. O. Tocho are with Centro de Investigaciones Opticas, 1900 La Plata, Argentina.

IEEE Log Number 9037366. drogen. In the next section we discuss the flowing hollow cathode discharge used in the experiments.

\section{Flowing Hollow Cathode Discharge Laser SYSTEM}

The ideal plasma for a recombination laser should have energetic electrons for efficient ionization and a large concentration of cool electrons for rapid recombination. Highvoltage electron beam glow discharges or hollow cathode discharges can be used to generate negative glow plasmas in which energetic beam electrons and low-energy thermalized electrons coexist. In these plasmas, the thermalized secondary electrons have a temperature that is typically $0.1 \mathrm{eV}$ [11], and strong excitation of radiative transitions by collisional recombination is often observed. The energetic beam electrons efficiently produce the necessary ionization; however, in the case of recombination lasers, they can also adversely affect the generation of population inversions by exciting the laser lower level through electron impact collisions [4], [12]. A fast gas flow can be used to expand the already supercooled negative glow plasma outside the ionization region thereby creating a recombining plasma without energetic electrons. An additional benefit of the fast flow is further cooling of the plasma.

A schematic representation of the flowing hollow cathode laser system used for the excitation of recombination laser action is shown in Fig. 1. Fig. 2 shows a photograph of the discharge setup. A discharge is established between a hollow cathode and a mesh anode. The cathode has a slot $4 \mathrm{~cm}$ long, $1.2 \mathrm{~cm}$ deep and $0.2 \mathrm{~cm}$ wide. For operation, the discharge setup is enclosed in a stainless steel vacuum envelope (not shown), and a gas flow is established through the anode mesh and cathode slot at a rate of 0.5 to $6 \mathrm{~L} / \mathrm{min}$ measured at 760 torr. The hollow cathode is made of the selected laser material and is soldered into a water-cooled copper body. Metal vapor is produced at room temperature by sputtering of the hollow cathode material. When helium is used as the buffer gas, argon or neon is also added to enhance cathode sputtering. A rotary pump with a pumping rate of $1000 \mathrm{~L} / \mathrm{min}$ is used to initially evacuate the vacuum chamber to a pressure of $10^{-3}$ torr and to establish the gas flow. 


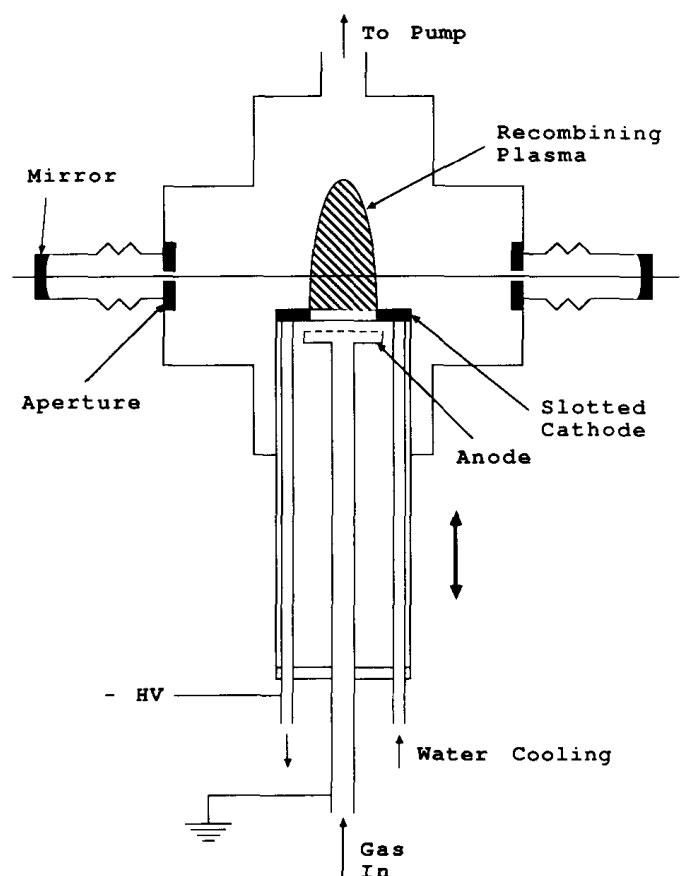

Fig. 1. Schematic representation of the flowing hollow cathode laser system. The discharge can be moved with respect to the axis of the optical cavity.

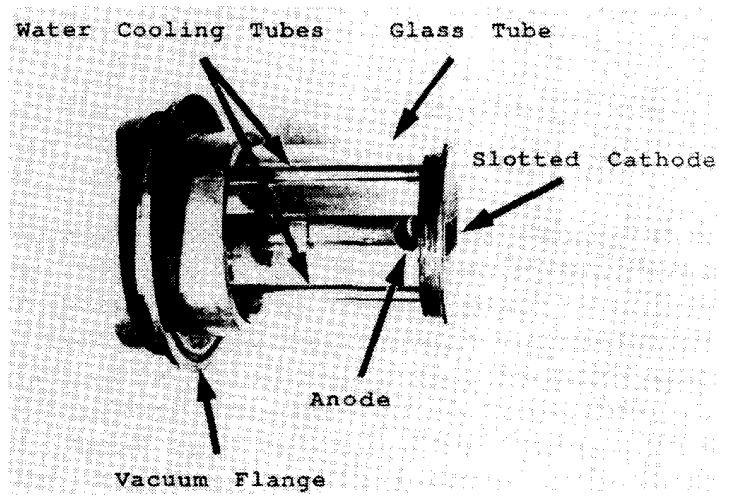

Fig. 2. Photograph showing discharge structure of the flowing hollow cathode device. The vacuum chamber is not shown.

In the work described in this paper, glow discharges were created using pulsed and dc power excitation. Pulsed currents reaching $35 \mathrm{~A}$ with pulsewidths between 10 and $50 \mu \mathrm{s}$ at a frequency of $500 \mathrm{~Hz}$ and dc currents up to $2 \mathrm{~A}$ were used for the excitation. In the latter case, a $500 \Omega$ ballast resistance was used in series with the discharge.

Following gas breakdown, a dense negative glow develops within the cathode slot, and a short positive column links it to the anode. The plasma in the slot is expanded out by the gas flow to form a low-temperature recombining plasma plume downstream of the cathode. The entire discharge structure is mounted in a glass tube that can be displaced with respect to the axis of an optical resonator using a dynamic vacuum seal. The ability to move the discharge assembly allows the exploration of laser action in different regions of the recombining plasma jet.

The optical cavity for the laser experiments was made of two mirrors with $2 \mathrm{~m}$ radius of curvature placed approximately $70 \mathrm{~cm}$ apart. Two sets of mirrors were used: one set had a highly reflective dielectric coating in the $1.0-1.5 \mu \mathrm{m}$ spectral region, and the other was highly reflective in the 1.5-2.0 $\mu \mathrm{m}$ spectral region. All of the experiments were done with these highly reflective mirrors, and no attempt was made to increase the laser output intensity by selecting an optimized mirror transmissivity.

\section{The Electron Temperature of the Flowing Afterglow of a Hollow Cathode Discharge}

Due to the $T_{e}{ }^{-4.5}$ dependence of the collisional recombination rate [13], the electron temperature $T_{e}$ plays an important role in recombination laser schemes. We have measured the electron temperature of the recombining plasma plume of a flowing hollow cathode discharge as a function of position. The study was performed in the same discharge used to obtain $\mathrm{CW}$ recombination laser action in the $1.43 \mu \mathrm{m}$ line of $\mathrm{CdI}[10]$. We employed the same spectroscopic technique [14] recently used to measure the electron temperature evolution of the plasma of a SPER laser [2]. While in the recombining plasma plume, population inversions are created among low lying levels, levels of sufficiently high energy remain in or near local thermodynamic equilibrium. The emission of the HeI lines in the $2 s{ }^{3} S-n p{ }^{3} P$ series was measured, and the electron temperature was determined from the relative intensity of levels in local thermodynamic equilibrium [15]. The intensities of the $\mathrm{HeI}$ lines were corrected to take into account the response of the optical system as determined by an NBS calibrated tungsten ribbon lamp.

Fig. 3 illustrates the measured variation of the electron temperature in the recombining plume as a function of distance from the hollow cathode. Data was obtained for discharge currents of 420 and $725 \mathrm{~mA}$. A unique property of negative glows is that the thermalized group of electrons in the discharge is already supercooled under stationary conditions. Further cooling of the plasma is observed downstream in the afterglow. At a dc current of $725 \mathrm{~mA}$, the electron temperature at $1.0 \mathrm{~cm}$ from the cathode, the optimum position for laser action in the $1.43 \mu \mathrm{m}$ line of CdI [10], was measured to be $890 \pm 40 \mathrm{~K}$. At this temperature, ion and electron densities slightly above 1 . $10^{12} \mathrm{~cm}^{-3}$ are computed to be necessary to sustain $\mathrm{CW}$ laser oscillation using a plasma a few $\mathrm{cm}$ in length. This density is readily achievable in the flowing afterglow of $\mathrm{dc}$ hollow cathode discharges. A maximum gain of $0.35 \%$ $\mathrm{cm}^{-1}$ was measured for the $1.43 \mu \mathrm{m}$ line of CdI when the discharge current was $800 \mathrm{~mA}$ in a $4 \mathrm{~cm}$ long discharge 


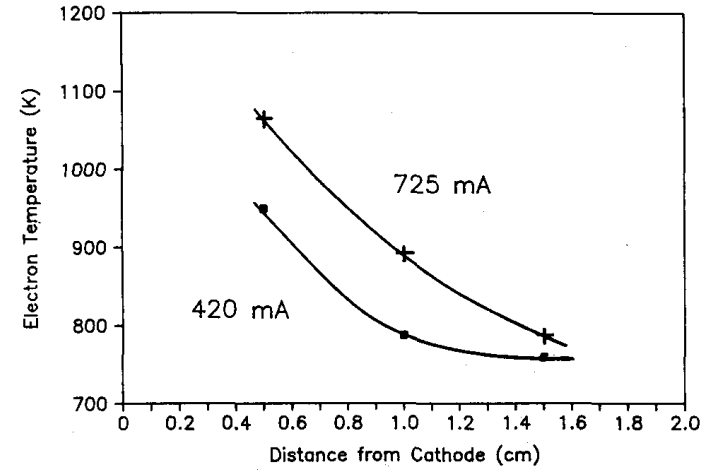

Fig. 3. Electron temperature in the flowing afterglow as a function of distance from the hollow cathode for two dc discharge currents. Helium is used as the buffer gas and the cathode is made of cadmium.

[10]. Larger discharge currents increase the plasma density above the collisional deexcitation limit [16] and cause a decrease in the gain.

\section{ReCOMbination LASING IN LEAD}

Two lead laser transitions were observed under pulsed discharge excitation in the flowing afterglow when the cathode was fabricated of lead. The measured laser wavelengths are (13 $102 \pm 2) \AA$ and $(13216 \pm 2) \AA$ and are assigned to the $13100.1 \AA$ line of $\mathrm{PbI}\left(7 p^{3} P_{1}-7 s^{3} P_{1}{ }^{\circ}\right)$ and the $13216.9 \AA$ line of PbII $\left(6 f^{2} F_{7 / 2}{ }^{\circ}-7 d^{2} D_{5 / 2}\right)$, respectively [17], [18]. Wood II, et al. [3] and Silfvast et al. [2] have reported a $\mathrm{PbI}$ laser transition at $13080 \AA$ using a $\mathrm{CO}_{2}$ laser-produced plasma and a segmented discharge, respectively, and designated it as the $13100.1 \AA$ transition. Zhukov et al. previously observed the 13216.9 $\AA$ laser transition of PbII in a pulsed positive column discharge [1].

The output intensity of the PbI and PbII laser lines as a function of distance between the cathode and the optical resonator axis for two different discharge currents is shown in Fig. 4. The PbI transition at $13100.1 \AA$ was observed to lase in discharges with either a He-Ar mixture or pure Ar as the buffer gas. Based on this fact and from the spatial distribution of the laser output which peaks at a distance $0.5-1.0 \mathrm{~cm}$ from the cathode, where the density of energetic electrons is negligible, it is inferred that the $\mathrm{PbI}$ line is an electron-ion recombination excited laser transition.

The PbII laser transition occurs closer to the cathode and is thought to be dominantly excited by the recombination of PbIII ground state ions. Zhukov et al. [1] have attributed the excitation of this laser transition in the temporal afterglow of a positive column glow discharge to electron-ion recombination of PbIII ground state ions created by the collisions of lead atoms with helium ions:

$$
\begin{aligned}
\mathrm{He}^{+} & \left(1 s^{2} S_{1 / 2}\right)+\mathrm{Pb}\left(6 p^{2}{ }^{3} P_{0}\right) \rightarrow \mathrm{Pb}^{++}\left(6 s^{2}{ }^{1} S_{0}\right) \\
& +\mathrm{He}\left(1 s^{2}{ }^{1} S_{0}\right)+e^{-}+\Delta E(2.1 \mathrm{eV}) .
\end{aligned}
$$

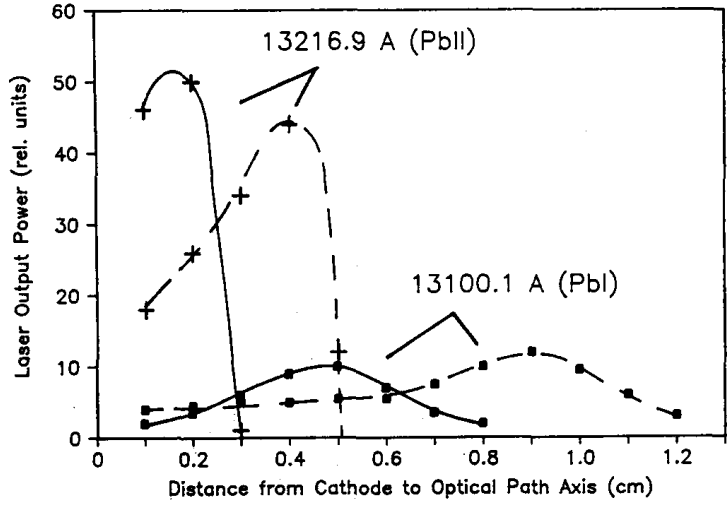

Fig. 4. Laser output of the two $\mathrm{Pb}$ laser transitions as a function of distance between the cathode and the optical path axis at a discharge current of $5 \mathrm{~A}$ (solid line) and $10 \mathrm{~A}$ (dashed line). The current pulsewidth was $20 \mu \mathrm{s}$. Gas flows were $1.3 \mathrm{~L} / \mathrm{min}$ for $\mathrm{Ar}$ and $4 \mathrm{~L} / \mathrm{min}$ for He. Two 2 $\mathrm{mm}$ diameter optical apertures were employed for spatial resolution.

This type of hybrid Duffendack-Penning reaction has been confirmed to occur with high efficiency in a $\mathrm{He}-\mathrm{Pb}$ afterglow [19]. In a helium afterglow with an ion density of $10^{11} \mathrm{~cm}^{-3}$ and a He $\left(2 s^{3} S_{1}\right)$ metastable density of $10^{10}$. $\mathrm{cm}^{-3}$, the excitation of highly excited states of singlyionized lead was observed to be as strong as the direct excitation of lower lying levels by conventional Penning reactions [19].

Penning ionization reactions between the He $\left(2 s^{1} S_{0}\right)$ metastable state and the ground state lead atoms described by

$$
\begin{gathered}
\mathrm{He}\left(2 s^{1} S_{0}\right)+\mathrm{Pb}\left(6 p^{2}{ }^{3} P_{0}\right) \rightarrow \mathrm{He}\left(1 s^{2}{ }^{1} S_{0}\right)+\mathrm{Pb}^{+*} \\
\cdot\left(6 f^{2} F_{7 / 2}{ }^{\circ}\right)+e^{-}+\Delta E(0.44 \mathrm{eV})
\end{gathered}
$$

are energetically allowed, and consequently could also contribute to the excitation of the $\mathrm{PbII}$ laser transition. However, in flowing afterglow helium experiments the only metastable atoms present in quantities detectable by optical absorption are those in the $\mathrm{He}\left(2 s^{3} S_{1}\right)$ level [19]. Also, excitation of the laser upper level from the more highly populated $\mathrm{He}\left(2 s^{3} S_{1}\right)$ level is not energetically allowed. Consequently while Penning excitation probably makes a contribution to the excitation of the $\mathrm{Pb}^{+*}$ ( $6 f$ ${ }^{2} F_{7 / 2}{ }^{\circ}$ ) state, recombination from doubly ionized lead is likely to be the dominant excitation path.

The plots of Fig. 4 also depict that an increase in the excitation current causes the position corresponding to the peak of the laser intensity to move away from the cathode. This dependence could be due to the increased value of the electron temperature at higher currents which causes the region of maximum recombination to move away from the cathode or to a higher electron density which results in increased superelastic electron deexcitation of thè upper laser levets. When the electron density in the region closer to the cathode becomes excessive, the position of optimum gain moves downstream. 


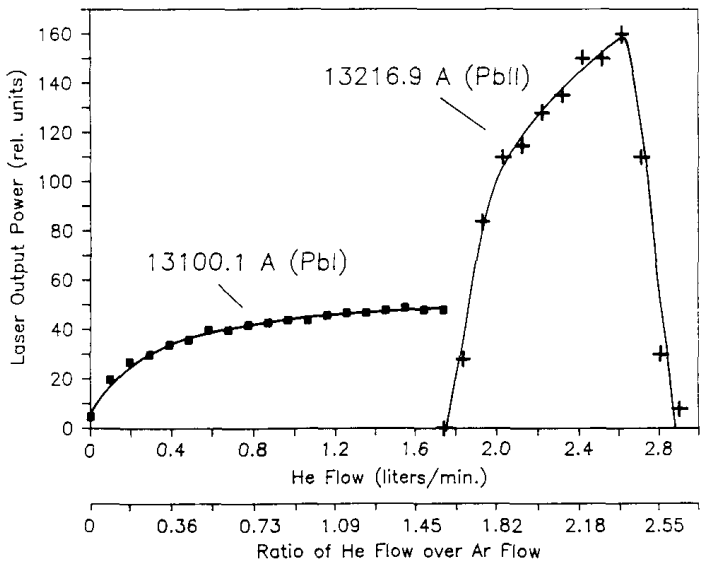

(a)

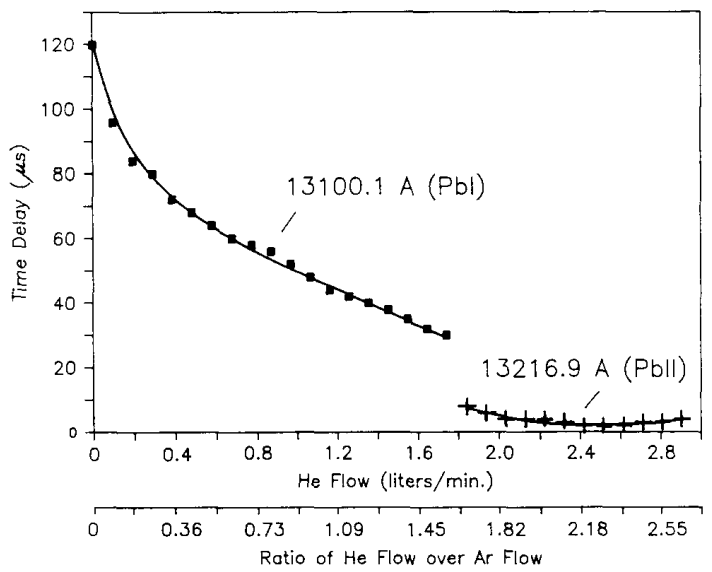

(b)

Fig. 5. (a) Laser output intensity and (b) time delay for the $13100.1 \AA$ $\mathrm{PbI}$ and $13216.9 \AA \mathrm{PbII}$ laser transition as a function of He flow. Discharge current was $7 \mathrm{~A}$ with a pulsewidth of $30 \mu \mathrm{s}$. Ar flow remained constant at $1.1 \mathrm{~L} / \mathrm{min}$. Distance between cathode and optical path axis was $0.1 \mathrm{~cm}$. No optical apertures were used.

Fig. 5 illustrates the variation of the laser output intensity and the time delay for the onset of both laser transitions with respect to the end of the current pulse as a function of the He flow. A constant flow of argon at a rate of $1.1 \mathrm{~L} / \mathrm{min}$ was used. The laser output intensity of the $\mathrm{PbI}$ recombination laser transition increased while the time delay decreased as $\mathrm{He}$ was added to the flow. This result is probably caused by the more efficient cooling of the plasma which increased the electron-ion recombination rate. The laser output of the PbII laser transition did not occur until the He flow was greater than the argon flow. This effect shows that the excitation of this laser transition is helium dependent and eliminates the possibility of direct electron impact excitation of the PbII laser transition. The minimum helium flow at which the PbII transition lased was $1.7 \mathrm{~L} / \mathrm{min}$, and the laser intensity increased for larger He flows until the flow was $2.6 \mathrm{~L} / \mathrm{min}$. The time

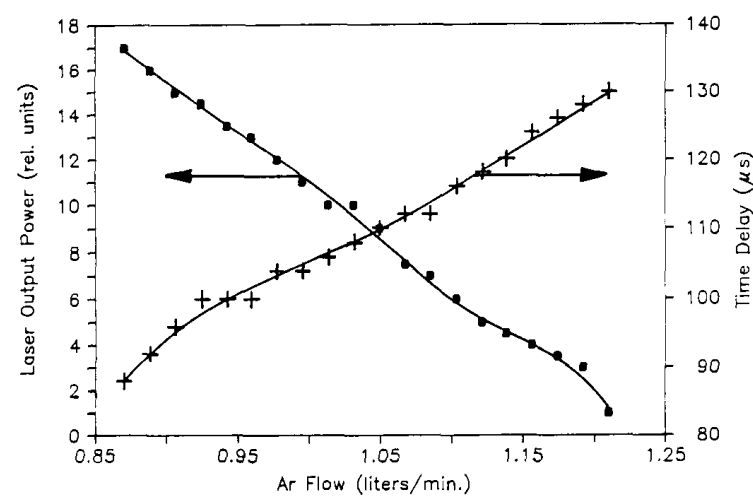

Fig. 6. Laser output intensity ( $\square$ ) and time delay $(+)$ between the laser pulse and the end of the current pulse for the $13100.1 \AA$ PbI laser transition as a function of the Ar flow. Discharge current was $7 \mathrm{~A}$ with a pulsewidth of $30 \mu \mathrm{s}$. Distance between cathode and optical path axis was $0.1 \mathrm{~cm}$. No optical apertures were used.

delay was simultaneously observed to decrease slightly. This increase in the laser output and decrease in the time delay is attributed to an increased recombination rate and a higher excitation of the laser upper level. The drop in the laser output for a helium flow above $2.6 \mathrm{~L} / \mathrm{min}$ was accompanied by a slight increase in the time delay. This phenomena is possibly associated with a decrease in cathode sputtering.

Fig. 6 shows the dependence of the laser intensity of the PbI $13100.1 \AA$ line and its time delay with respect to the end of the current pulse as a function of the argon gas flow rate for the case in which the He flow is reduced to zero. These plots show that as the argon flow increased the laser output diminished and the time delay increased.

Fig. 7 gives the change in the laser output intensity and the time delay as a function of discharge current. The $\mathrm{PbI}$ and $\mathrm{PbII}$ laser transition intensities increased and the corresponding time delay decreased when the current was increased from the threshold values to 6 and $5 \mathrm{~A}$, respectively. This increased laser intensity and decreased time delay corresponded to an increase of the electron-ion recombination rate and of the small-signal gain with larger currents. However, when the input current was increased above these values the laser output decreased and the time delay increased. This behavior is probably due to the increase in superelastic electron deexcitation of the laser upper level due to a higher electron density. Also, the increase of the plasma temperature at the highest currents could contribute to the increased delay and decreased intensity of the laser pulse. No $\mathrm{CW}$ laser oscillation was observed in lead for dc discharge currents up to $2 \mathrm{~A}$.

\section{LASER ACtion IN TIN}

Replacing the slotted lead cathode with one made of tin enabled laser-oscillation in ionic tin. The measured wavelength of this transition was $(10737 \pm 2) \AA$. This line is assigned to the SnII transition of $10738.7 \AA$ $\left(5 f^{2} F_{5 / 2}{ }^{\circ}-6 d^{2} D_{5 / 2}\right)[17],[18]$. Zhukov et al. observed 


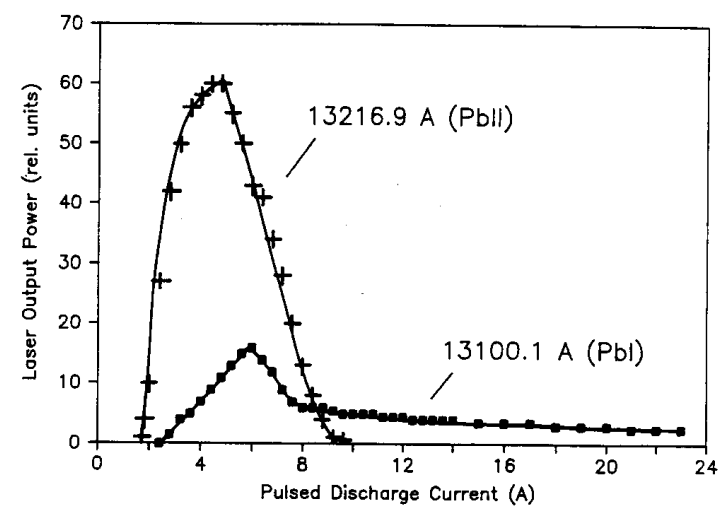

(a)

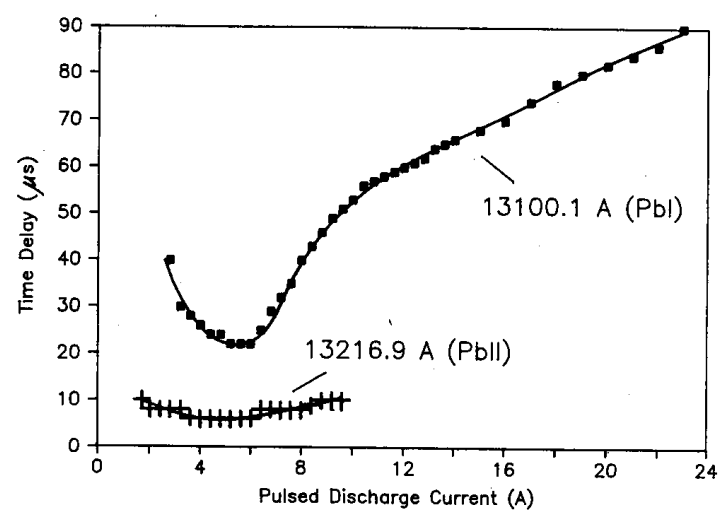

(b)

Fig. 7. (a) Laser output intensity and (b) time delay for both the 13100.1 $\AA \mathrm{PbI}$ and $13216.9 \AA \mathrm{PbII}$ laser transitions as a function of the discharge current. Current pulsewidths were $30 \mu \mathrm{s}$. Distance between cathode and optical path axis for the $\mathrm{PbI}$ and $\mathrm{PbII}$ laser transitions was set at 0.5 and $0.2 \mathrm{~cm}$, respectively. Gas flows were $1.3 \mathrm{~L} / \mathrm{min}$ for $\mathrm{Ar}$ and 4 $\mathrm{L} / \mathrm{min}$ for He. No optical apertures were used.

a laser transition in SnII at a wavelength of $10740 \AA$ and assigned it to the $5 f^{2} F_{7 / 2}{ }^{\circ}-6 d^{2} D_{5 / 2}$ transition [1] corresponding to a wavelength of $10743 . \overline{3} \AA$ [17], [18].

Zhukov et al. [1] attributed the SnII laser transition observed during the afterglow of a positive column glow discharge to an electron-ion recombination reaction of doubly-ionized metal vapor ions as was the case of the $\mathrm{PbII}$ transition. SnIII ground state ions are created by

$$
\begin{aligned}
\mathrm{He}^{+} & \left(1 s^{2} S_{1 / 2}\right)+\mathrm{Sn}\left(5 p^{2}{ }^{3} P_{0}\right) \rightarrow \mathrm{Sn}^{++}\left(5 s^{2}{ }^{1} S_{0}\right) \\
& +\mathrm{He}\left(1 s^{2}{ }^{1} S_{0}\right)+e^{-}+\Delta E(2.6 \mathrm{eV})
\end{aligned}
$$

The He $\left(2 s^{3} S_{1}\right)$ metastable level lies $0.12 \mathrm{eV}$ above the laser upper level of the SnII laser transition, and excitation of the $\mathrm{Sn}^{+*}\left(5 f^{2} F_{5 / 2}{ }^{\circ}\right)$ through a Penning ionization reaction involving this state is energetically allowed. Nevertheless, reactions of this type have been observed to have the highest probability of occurrence when the energy difference $\Delta E$ is of the order of several $\mathrm{eV}$ [19] and consequently can be expected to favor the

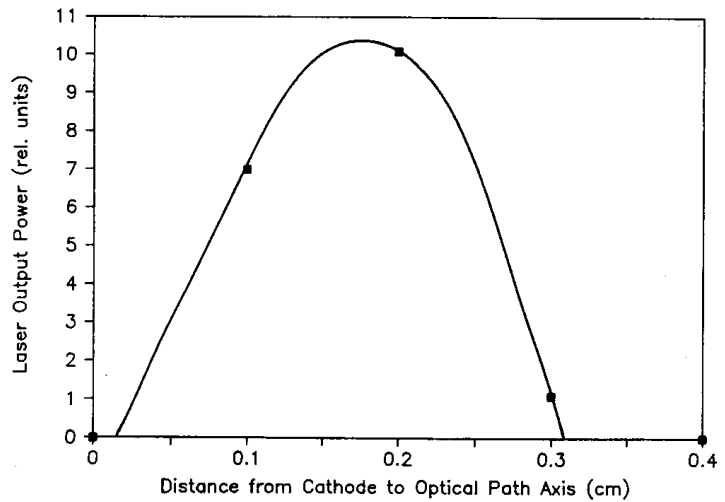

Fig. 8. Laser output intensity of the 10738.7 SnIl laser transition as a function of distance between the cathode and optical path axis. Discharge current was $6 \mathrm{~A}$ with a pulsewidth of $27 \mu \mathrm{s}$. Gas flows were 1.3 $\mathrm{L} / \mathrm{min}$ for $\mathrm{Ar}$ and $4 \mathrm{~L} / \mathrm{min}$ for He. Two $2 \mathrm{~mm}$ diameter optical apertures were used for spatial resolution.

excitation of lower levels. Also in the case of excitation of the $\mathrm{Sn}^{+} *\left(5 f^{2} F_{5 / 2}{ }^{\circ}\right)$ level, this Penning reaction is unlikely since it does not conserve total spin as required by the Wigner spin rule [20].

A plot of the laser output intensity as a function of the distance between the slotted cathode and the optical path axis is given in Fig. 8. The gas flows were $1.3 \mathrm{~L} / \mathrm{min}$ for $\mathrm{Ar}$ and $4 \mathrm{~L} / \mathrm{min}$ for He. The SnII transition was unable to lase $\mathrm{CW}$ when a dc current of up to $0.8 \mathrm{~A}$ was applied to the slotted cathode. The discharge arced at larger currents before the threshold for $\mathrm{CW}$ laser action could be achieved.

\section{Recombination Lasing in Atomic Zinc and Enhanced Laser Intensity by Hydrogen Plasma CoOling}

Recombination lasing was also achieved in $\mathrm{ZnI}$ when the slotted cathode was made of this material. The observed laser wavelength was $(13152 \pm 2) \AA$, and it corresponds to a $\mathrm{ZnI}$ recombination laser transition previously reported by Wood et al. [3] which was assigned to the $13151.42 \AA$ line $\left(5 p^{3} P_{1}{ }^{\circ}-5 s^{3} S_{1}\right)$ [17], [18]. For this laser transition to occur, the gas flows were adjusted to 1.3 L/min for $\mathrm{Ar}$ and $4 \mathrm{~L} / \mathrm{min}$ for $\mathrm{He}$.

The addition of hydrogen to the discharge was observed to significantly enhance the laser output intensity by cooling of the electron gas as illustrated by the oscilloscope photographs shown in Fig. 9. This figure also shows how the time delay between the end of the current pulse and the beginning of the laser pulse is reduced from 80 to 16 $\mu \mathrm{s}$ with the addition of hydrogen. Hydrogen molecules, which are lighter than helium atoms, are better conductors of heat and thermalize the electron gas to a lower temperature throughrmore efficient elastic collisions. Consequently, the addition of $\mathrm{H}_{2}$ can be expected to enhance the laser output, in agreement with the experimental observation. A similar effect was previously observed by 


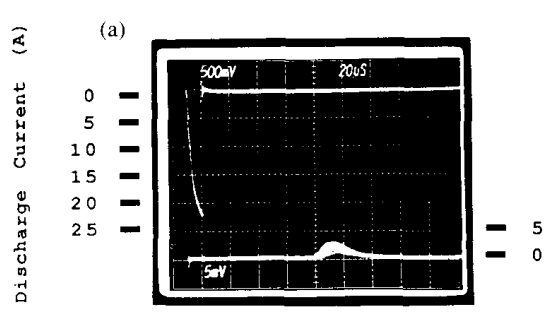

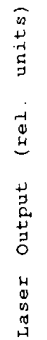

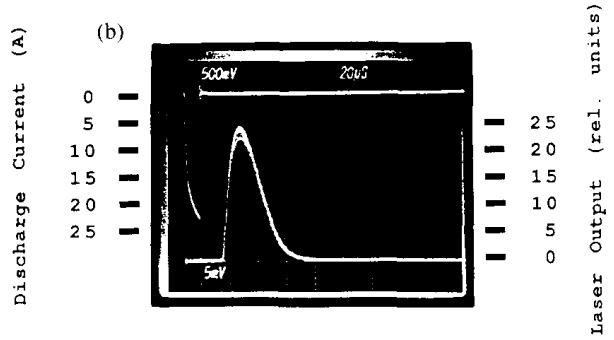

Fig. 9. (a) Discharge current (upper trace and inverted) and laser output intensity (lower trace) of the $13151.4 \AA \mathrm{ZnI}$ laser transition for discharge pulses without $\mathrm{H}_{2}$. Gas tlows were $1.3 \mathrm{~L} / \mathrm{min}$ for $\mathrm{Ar}$ and $4 \mathrm{~L} / \mathrm{min}$ for He. (b) Same as in part (a) but with the addition of $\mathrm{H}_{2}$. Gas flows were $1.5 \mathrm{~L} / \mathrm{min}$ for $\mathrm{H}_{2}, 1 \mathrm{~L} / \mathrm{min}$ for $\mathrm{Ar}$ and $3 \mathrm{~L} / \mathrm{min} \mathrm{He}$. The distance between the cathode and optical path axis was $0.5 \mathrm{~cm}$

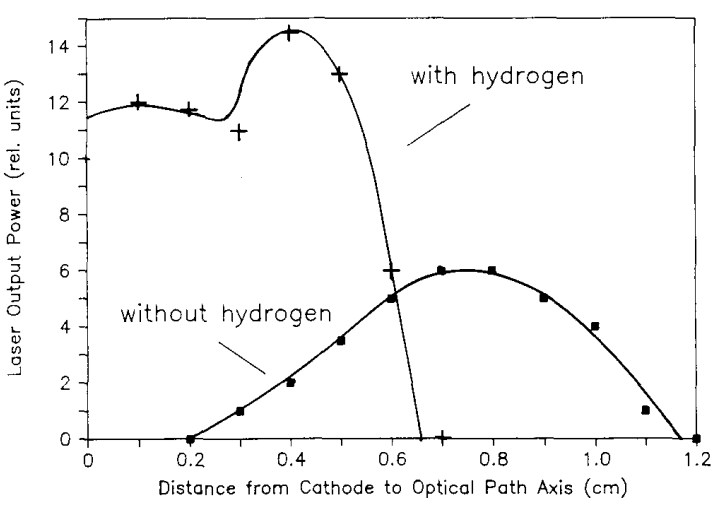

Fig. 10. Laser output intensity of the $13151.4 \AA \mathrm{ZnI}$ recombination laser transition as a function of the distance between the cathode and optical cavity axis. Gas flows without $\mathrm{H}_{2}$ were $1.2 \mathrm{~L} / \mathrm{min}$ for Ar and $4 \mathrm{~L} / \mathrm{min}$ for $\mathrm{He}$. Gas flows with $\mathrm{H}_{2}$ were $1.5 \mathrm{~L} / \mathrm{min}$ for $\mathrm{H}_{2}, 1 \mathrm{~L} / \mathrm{min}$ for $\mathrm{Ar}$ and $3 \mathrm{~L} / \mathrm{min}$ for He. Discharge current pulses were $15 \mathrm{~A}$ with a pulsewidth of $10 \mu \mathrm{s}$. Two $2 \mathrm{~mm}$ diameter optical apertures were used for spatial resolution.

Zhukov et al. for recombination lasing in a pulsed positive column discharge [1].

Fig. 10 shows the variation of the output intensity of the $\mathrm{ZnI}$ recombination laser transition as a function of the distance between the cathode and optical cavity axis for discharges with and without hydrogen. The addition of hydrogen caused the recombination reactions to be enhanced and laser action to occur closer to the cathode. Fig. 11 illustrates the laser output intensity and the time

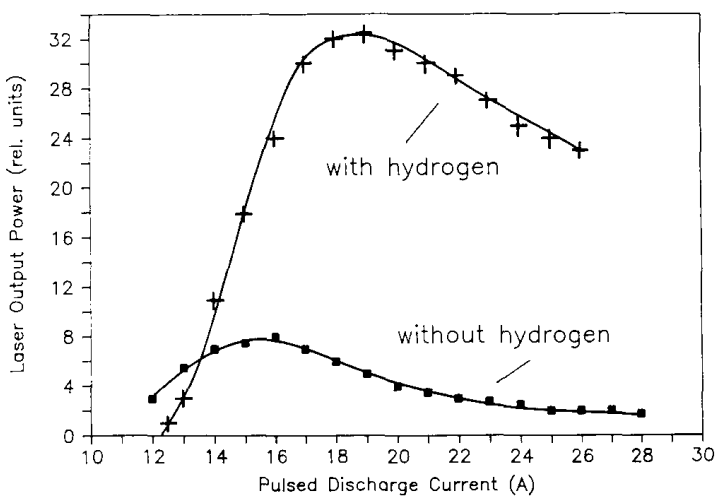

(a)

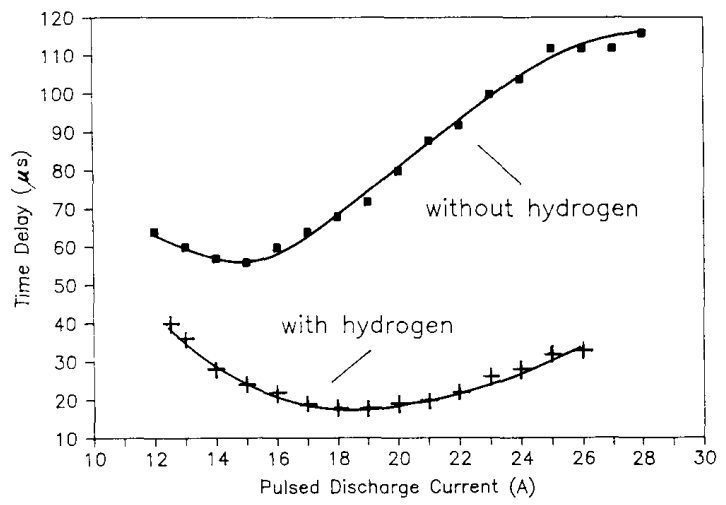

(b)

Fig. 11. (a) Laser output intensity and (b) time delay of the $13151.4 \AA$ $\mathrm{ZnI}$ laser transition as a function of the discharge current for discharges with and without hydrogen. Gas flows with and without hydrogen were the same as in Fig. 10. The discharge current pulsewidth was $10 \mu \mathrm{s}$. Two $2 \mathrm{~mm}$ optical apertures were used. Distance from cathode to optical path axis without $\mathrm{H}_{2}$ was $0.8 \mathrm{~cm}$ and with $\mathrm{H}_{2}$ was $0.5 \mathrm{~cm}$.

delay between the end of the discharge current pulse and the beginning of the laser pulse as a function of current for both cases. The addition of a hydrogen flux of 1.3 $\mathrm{L} / \mathrm{min}$ to the plasma caused the laser output peak to increase and the time delay to decrease. These phenomena are a consequence of an increase in the electron-ion recombination rate. The threshold for $\mathrm{CW}$ laser oscillation was found to be above the maximum value of the discharge current investigated, $1.5 \mathrm{~A}$.

\section{Continuous Wave ArI Recombination Laser}

$\mathrm{CW}$ recombination laser action in neutral argon at $12702.2 \AA$ was obtained in the flowing afterglow of a dc hollow cathode discharge containing argon. The laser radiation corresponds to the ArI $\left(3 d^{\prime}[3 / 2]_{1}{ }^{\circ}-4 p^{\prime}[1 / 2]\right)$ transition [17], [18]. The results reported herein correspond to a discharge with a slotted cathode made of cast iron, but we also observed ArI laser oscillation with cathodes made of tin, copper, and cadmium. Solanki et al. previously reported pulsed oscillation of this laser tran- 


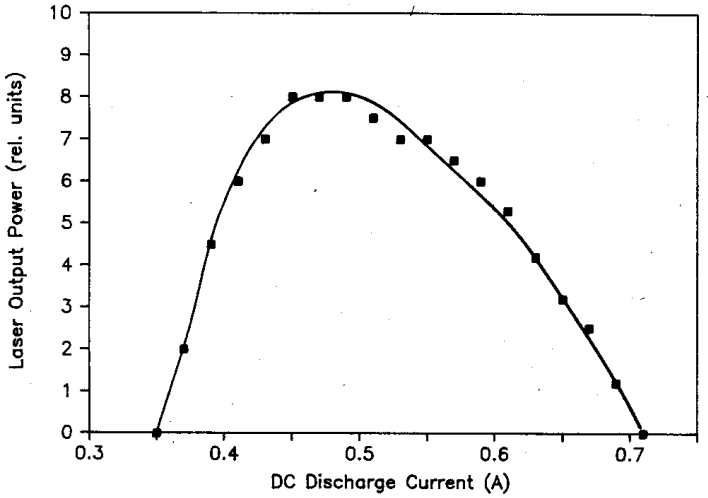

Fig. 12. CW laser output of the $12702.2 \AA$ Arl recombination laser transition as a function of discharge current. Distance from the cathode to the optical path axis was $0.5 \mathrm{~cm}$. Gas flows were $0.3 \mathrm{~L} / \mathrm{min}$ for $\mathrm{Ar}$ and $5.5 \mathrm{~L} / \mathrm{min}$ for $\mathrm{He}$.

sition in a stationary (nonflowing) hollow cathode discharge caused by contributions of both electron impact excitation and recombination [21]. CW laser oscillation was also observed and attributed to electron impact excitation [21]. This ArI transition has also been observed to be superradiant [22].

$\mathrm{CW}$ recombination laser oscillation was observed when the axis of the optical resonator was placed at $0.5 \mathrm{~cm}$ from the cathode. This is also the place at which maximum recombination laser intensity was obtained under pulsed excitation. Fig. 12 illustrates the variation of the $\mathrm{CW}$ laser intensity as a function of the discharge current. Laser oscillation was observed to have a threshold current of 0.35 $\mathrm{A}$, maximized at $0.47 \mathrm{~A}$, and ceased at a current of 0.71 A. The gas flows were $0.3 \mathrm{~L} / \mathrm{min}$ of $\mathrm{Ar}$ and $5.5 \mathrm{~L} / \mathrm{min}$ of He. This transition was also observed to oscillate in $\mathrm{H}_{2}$-Ar mixtures.

A complex spatial distribution of the laser intensity of this line was observed under pulsed excitation. Fig. 13 shows that in this case there are two peaks in the intensity distribution. One of them occurs at $0.5 \mathrm{~cm}$ from the cathode and is likely to be due to collisional recombination. The other region of gain takes place near the cathode, and it is most probably caused by a different excitation mechanism. The variation of the laser output intensity and the delay between the end of the current pulse and the beginning of the laser pulse as a function of discharge current are illustrated in Fig. 14. The measurements were obtained introducing in the resonator two $2 \mathrm{~mm}$ diameter optical apertures to distinguish the emission from the region near the cathode from that originating at $0.5 \mathrm{~cm}$ from the cathode:

As shown in this figure, the time delay of the laser pulse for the portion of the plasma $0.5 \mathrm{~cm}$ from the cathode decreased when the input current was changed from the threshold value of 1.25 to $5 \mathrm{~A}$. This time delay decrease and the corresponding increase in the laser output intensity are attributed to an increase in the electron-ion recombination rate due to a higher electron density. How-

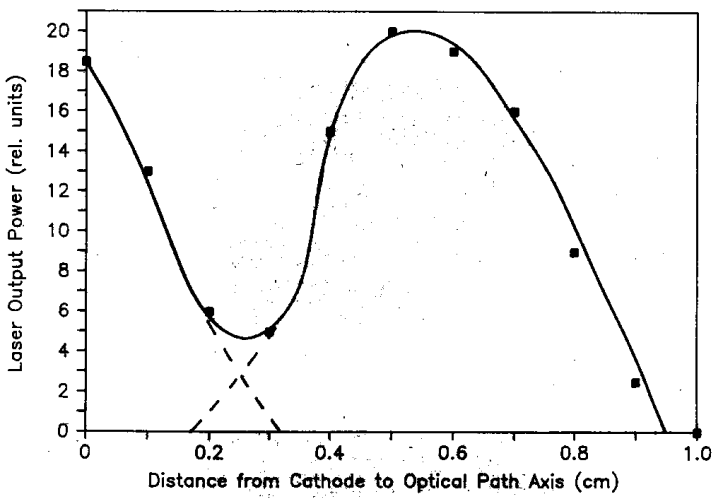

Fig. 13. Laser output of the $127022 \AA$ ArI laser transition as a function of distance between the cothode and optical path axis. Discharge current pulses were $7 \mathrm{~A}$ with a pulsewith o 20 us. Gas flows were $0.6 \mathrm{~L} / \mathrm{min}$ for $\mathrm{Ar}$ and $5.5 \mathrm{~L} / \mathrm{min}$ fort He. THo $\mathrm{t}$ min dianieter apertures were introduced inside of the cavity to obtaln the spatial resolution.

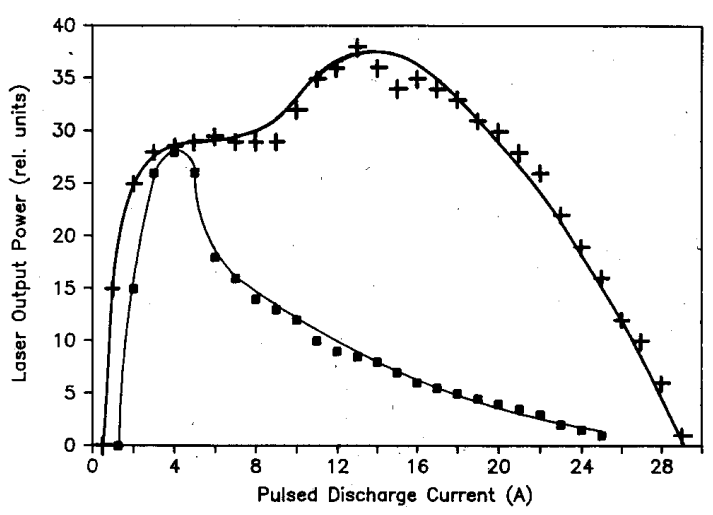

(a)

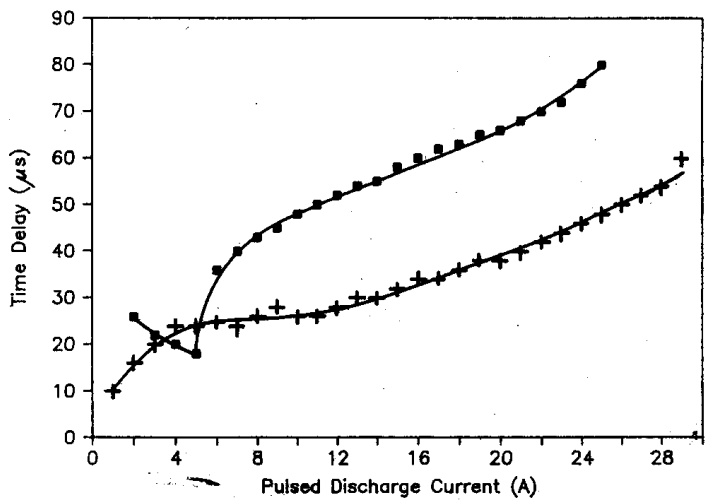

(b)

Fig. 14. (a) Laser output intensity and (b) time delay of the $12702.2 \AA$ Arl laser transition at $0.0 \mathrm{~cm}(+)$ and $0.5 \mathrm{~cm}(D)$ from the cathode as a function of discharge current. Current pulsewidths were $20 \mu \mathrm{s}$. Gas flows were $0.3 \mathrm{~L} / \mathrm{min}$ for $\mathrm{Ar}$ and $5.5 \mathrm{~L} / \mathrm{min}$ for He. Two $2 \mathrm{~mm}$ diameter apertures were employed to obtain the spatial resolution. 
ever, when the current was increased above $5 \mathrm{~A}$, the electron density became excessive and the laser output decreased. For the region of the afterglow near the cathode, the time delay for the onset of the laser pulse increased from 10 to $60 \mu$ s as the current increased from 1 to $29 \mathrm{~A}$.

Electrons with sufficient energy to excite this transition might be scattered out of the cathode slot into the region near the cathode. However, they are expected to cool below the excitation energy of the laser upper level of the ArI transition in less than $1 \mu \mathrm{s}$, and consequently electron impact excitation cannot be responsible for the inversion observed in the afterglow region near the cathode. A mechanism that could excite the laser action in this region is dissociative recombination of $\mathrm{Ar}_{2}{ }^{+}$ions [23], [24]. Calculated estimates of the rates of formation of $\mathrm{Ar}_{2}{ }^{+}$for the measured pressure of 12 torr are compatible with a gain coefficient value of $3 \cdot 10^{-3} \mathrm{~cm}^{-1}$, indicating that this is a viable excitation mechanism. Nevertheless, more detailed studies are needed to identify the dominant excitation mechanism responsible for gain in the vicinity of the cathode under pulsed excitation.

ArI was also observed to oscillate in a pulsed manner at a measured wavelength of $(12403 \pm 2) \AA$. This line is assigned to the ArI $12402.8 \AA$ transition $\left(3 d[3 / 2]_{1}{ }^{\circ}-\right.$ $\left.4 p[3 / 2]_{1}\right)$ [17], [18]. This line lased in the proximity of the cathode $(0.1 \mathrm{~cm})$ under the excitation of $10 \mathrm{~A}$ pulses $15 \mu$ s wide when the gas flows through a tin cathode were $1.1 \mathrm{~L} / \mathrm{min}$ of Ar and $2.5 \mathrm{~L} / \mathrm{min}$ of $\mathrm{H}_{2}$.

\section{Other Observed Laser Transitions}

Laser oscillation in neon and molecular hydrogen was also observed. The well-known $11522 \AA$ laser line of $\mathrm{NeI}$ [18] was observed to oscillate in the vicinity of the tin cathode when the gas flows were adjusted to $1.5 \mathrm{~L} / \mathrm{min}$ for $\mathrm{Ne}$ and $4 \mathrm{~L} / \mathrm{min}$ for He. The other two NeI laser transitions were assigned to the $11 \quad 177.5$ and $11515.0 \AA$ lines of $\mathrm{NeI}$ [18] and were observed to oscillate when the gas flows in a $\mathrm{Ne}-\mathrm{H}_{2}$ mixture were $1.3 \mathrm{~L} / \mathrm{min}$ for $\mathrm{Ne}$ and $1.3 \mathrm{~L} / \mathrm{min}$ for $\mathrm{H}_{2}$. These two transitions were observed to lase with the resonator axis aligned at $0.2 \mathrm{~cm}$ from the tin cathode and when the discharge current pulses were 15 A with a $15 \mu \mathrm{s}$ width.

During the experiments with the $\mathrm{Zn}$ cathode, molecular hydrogen was observed to lase at (13056 12 ) $\AA$, and the oscillation was assigned to correspond to the $13056.62 \AA\left(2 s^{1} \Sigma_{g}{ }^{+} P(4) 0-2 p^{1} \Sigma_{u}{ }^{+} P(4) 1\right)$ transition [25]. This transition was observed to lase with the gas flows at $1.3 \mathrm{~L} / \mathrm{min}$ for $\mathrm{H}_{2}, 1.1 \mathrm{~L} / \mathrm{min}$ for $\mathrm{Ar}$, and 3 $\mathrm{L} / \mathrm{min}$ for $\mathrm{He}$ when the input current was $15 \mathrm{~A}$ for a pulsewidth of $10 \mu \mathrm{s}$. Fig. 15 shows the output intensity of the $\mathbf{H}_{2}$ laser transition as a function of the distance between the cathode and the axis of the optical cavity.

\section{Summary}

Electron temperatures of less than $0.1 \mathrm{eV}$ were measured in the afterglow of a flowing hollow cathode discharge under stationary conditions. In this simple supercooled plasma device $\mathrm{CW}$ collisional recombination lasing

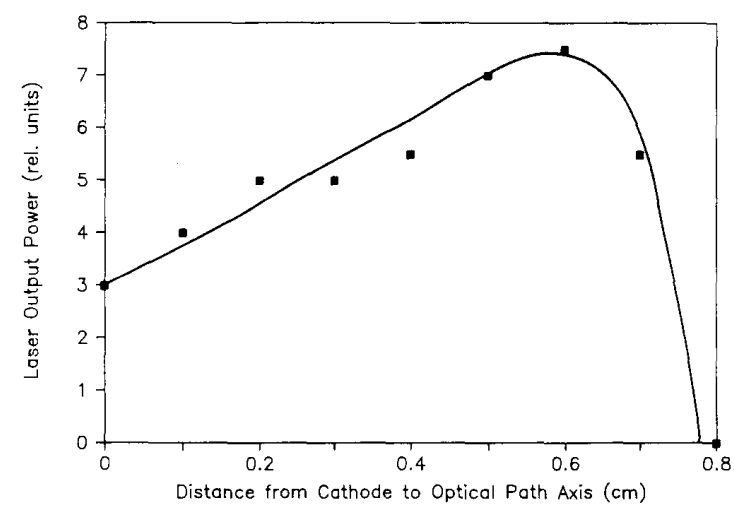

Fig. 15. Laser output of the $13056.6 \AA$ laser transition of $\mathrm{H}_{2}$ as a function of the distance between the cathode and optical cavity axis. Discharge current pulses were $20 \mathrm{~A}$ with a pulsewidth of $10 \mu \mathrm{s}$. Gas flows were the same as those of Fig. 9(b). Two $2 \mathrm{~mm}$ diameter optical apertures were employed.

has been obtained in discharges only $4 \mathrm{~cm}$ in length. The flowing negative glow plasma is the only medium which has been reported to generate $\mathrm{CW}$ recombination lasing for prolonged periods of time. $\mathrm{CW}$ laser oscillation has been obtained in $\mathrm{CdI}$ and ArI, and four other near-infrared recombination transitions were observed to oscillate in a pulsed mode in neutral and singly-ionized metal vapor atoms. While we made no attempts to optimize the output power of these infrared transitions, it can be shown theoretically that the maximum laser output power density that could be extracted from the recombining plasma plume for the measured electron temperature of $890 \mathrm{~K}$ would be limited to a fraction of a $\mathrm{mW} / \mathrm{cm}^{3}$ by collisional deexcitation of the laser upper level. Since the ratio between the collisional recombination and the collisional deexcitation rates scales as $T_{e}^{-4}$, additional cooling of the plasma is desirable. The addition of hydrogen has been shown to significantly increase the laser output pulse intensity, presumably by causing a decrease in the plasma temperature. Also, the limitation on the laser output power imposed by collisional deexcitation would be more relaxed for shorter wavelength transitions where the larger energy gap separating the upper laser levels from lower levels results in a reduced collisional deexcitation rate. However, the demonstration of $\mathrm{CW}$ recombination laser oscillation in the visible or ultraviolet will require stable discharge operation at a higher current.

\section{ACKNOWLEDGMENT}

The authors wish to thank T. Douglas for her assistance with the experiments and $M$. Villagran for his helpful discussions.

\section{REFERENCES}

[1] V. V. Zhukov, V. S. Kucherov, E. L. Latush, and M. F. Sem, "Recombination lasers utilizing vapors of chemical elements. II. Laser action due to transitions in metal ions," Sov. J. Quantum Electron., vol. 7, pp. 708-714, 1977. 
[2] W. T. Silfvast, L. H. Szeto, and O. R. Wood, II, "Simple metalvapor recombination lasers using segmented plasma excitation," Appl. Phys. Lett., vol. 36, pp. 615-617, 1980.

[3] O. R. Wood, II, J. J. Macklin, and W. T. Silfvast, "Neutral-atom recombination lasers in $\mathrm{CO}_{2}$ laser-vaporized target material," IEEE J. Quantum Electron., vol. QE-21, pp. 1714-1721, 1985.

[4] J. J. Rocca, H. L. Mancini, and B. Wernsman, "Cd recombination laser in a plasma generated by an electron beam," IEEE J. Quantum Electron., vol. QE-22, pp. 509-512, 1986.

[5] M. S. Butler and J. A. Piper, "High-pressure high-current transversely excited $\mathrm{Sr}^{+}$recombination laser," Appl. Phys. Lett., vol. 42, pp. 1008-1010, 1983.

[6] C. E. Little and J. A. Piper, "Average-power limitations of largeaperture self-heated $\mathrm{Ca}^{+}$afterglow-recombination lasers," Opt. Commun., vol. 68, pp. 282-286, 1988.

[7] T. Hara, K. Kodera, M. Hamagaki, K. Matsunaga, M. Inutake, and $T$. Dote, "Quasi-steady laser oscillation in the recombining hydrogen plasma," Japan. J. Appl. Phys., vol. 19, pp. L606-L608, 1980.

[8] E. M. Campbell, R. G. Jahn, W. F. Von Jaskowsky, and K. E. Clark, "Recombination lasing in a magnetoplasmadynamic arcjet," Appl. Phys. Lett, vol. 30, pp. 575-577, 1977.

[9] W. T. Silfvast, O. R. Wood, and J. J. Macklin, "CW recombination láser action in a cadmium vapor arc," Appl. Phys. Lett., vol. 42, pp. $347-349,1983$.

[10] J. J. Rocca, "CW recombination laser in a flowing negative glow plasma," Appl. Phys. Lett., vol. 47, pp. 1145-1147, 1985.

[11] Z. Yu, J. J. Rocca, G. J. Collins, and C. Y. She, "The energy of thermalized electrons in electron beam created helium discharges," Phys. Lett, vol. 96A, pp. 125-129, 1983.

[12] J. J. Rocca, H. L. Mancini, B. Wernsman, and G. Fetzer, "Recombination lasers excited by electron beams," in Proc. Int. Conf., Lasers 85 , pp. 805-810, 1985.

[13] E. Himov and J. G. Hirschberg, "Electron-ion recombination in dense plasmas," Phys. Rev, vol. 125, pp. 795-801, 1962.

[14] M. Villagran, M. Gallardo, J. O. Tocho, and J. J. Rocca, "The electron temperature in the plasma of a Spark-recombination laser," $J$. Appl. Phys., vol. 61, pp. 4447-4451, 1987.

[15] H. R. Griem, "Validity of local thermal equilibrium in plasma spectroscopy," Phys, Rev, , vol. 131, pp. 1170-1176, 1963.

[16] O. R. Wood, II and W. T. Silfyast, "Electron density and energy output limits of plasma-recombination lasers," Appl. Phys. Lett., vol. 41, pp. 121-123, 1982.

[17] C. E. Moore, Atomic Energy Levels, vols. I-III, Washington, DC U.S. GPQ, 1949, 1952, and 1958 .

[18] W. R Bernett, Jr,, Atomic Gas Laser Transition Data: A Critical Review. New York. IFI/Plenum, 1980.

[19] J. M. Green and C. E. Webb, "The production of excited metal ions in thermal energy charge transfer and penning reactions," J. Phys. $B$, vol. 7, pp. $1698-1711,1974$

[20] L. D. Schearer, "Ion polarization via penning collisions with optically pumped metastable helium," Phys. Rev. Lett., vol. 22, pp. 629$631,1969$.

[21] R. Solanki, E. L. Latush, W. M. Fairbank, Jr., and G. J. Collins, "New infrared laser transitions in copper and silver hollow cathode discharges," Appl. Phys, Lett, yol 34, pp. 568-570, 1979

[22] G. J. Linford, "High-gain treutral laser lines in pulsed noble-gas dischanges,"IEEE J. Ovantum Electron, vol. OE-8, po. 477-482, 1972

[23] H. L. Kramer, J. A. Herce, and E. E. Muschlitz, Jr., "Formation and collisional dissociation of heteronuclear rare-gas associative ions," J. Chem. Phys., vol. 56, pp. 4166-4170, 1972.

[24] F. Kannari, A. Suda, M. Obara, and T. Fujioka, "Theonetical simulation of electron-beam-excited Xenon-Chloride ( $\mathrm{XeCl}$ ) lasers,' IEEE J. Quantum Electron., vol. QE-19, pp. 1587-1600, 1983

[25] P. L. Kelley, B. Lax, and P. E. Tannenwald, Physics of Quantum Electronics, Conference Proceedings New York: McGraw-Hill, 1966.
B. Wernsman, photograph and biography not available at the time of publication.

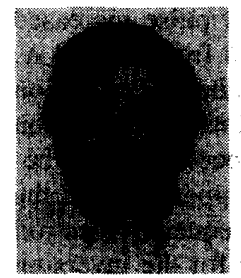

Jorge J. Rocca (S'80-M'83) received his diploma in physics from the University of Rosario, Argentina in 1978, and his Ph.D. degree from Colorado State University, Fort Collins, in 1983

He is currently an Associate Professor in the department of Electrical Engineering at Colorado State University.

His broad research interests include the development of new short-wavelength lasers and the physics of discharges and plasmas. His work has included the development of ion lasers excited by electron beams, the generation of intense electron beams from glow discharges, the demonstration of recombination lasing in negative glow plasmas and the stady of dense capillary discharges which he has proposed as possible source of short-wavelength recombination laser radiation.

Dr. Rocca received a National Science Foundation Presidential Young Investigator Award for 1985-1990 and he is also a recipient of the Halliburton Foundation Award. He is a member of the Optical Society of America.

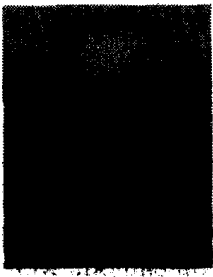

Hector L. Mancini was born in Buenos Aires, Argentina on February 16, 1945. He received the M.S. degree in electronics from the University of Buenos Aires in 1978

He joined the Laser Research Center of $\mathrm{CI}$ TEFA Buenos aires in 1969 working on gas lasers technology and applications, and population irversion mechanisms. He then became a Visiting Scientist with the National Institute of Optics, Italy, from 1979 to 1980 , and at Colorado State University ERC, in 1985 and 1988 . From 1980 to 1986, he taught physics at the Universidad Tecnologica Nacional where he became Associate Professor. From 1987 to the present he is a Full Professor with Department of Physics, San Luis University, Argentina, teaching courses on lasers and experimental physics. He is now Projects Leader at the Laser Center of CITEFA and a CONICET member. His current research interests are lasers, optics, and nonlinear dynamics.

Mr. Mancini is member of the Optical Society of America and the Asociacion Fisica Argentina.

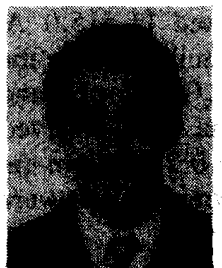

Daniel Schinca was born in Buenos Aires, Argentina on February 17, 1955. He recieved the MS and Ph.D. degrees in physics from La Plata University

Since 1978 he has been with the Optics Research Center (CIOp), La Plata, conducting research on spectroscopy and population mechanisms of gas molecular lasers. His current research interests include laser spectroscopy of gases and interests include laser spectroscopy of gases and Presently, he is an assistant professor with the Department of Physics, Lo Plata University and since 1988 has been with the Carrera del Investigador de la Comision de Investigaciones Cientificas de la Provincia de Buenos Aires.

Dr. Schinca is a member of the Asociacion Fisica Argentina

J. O. Tocho, photograph and biography not available at the time of publication. 